\title{
VITALITAS BAHASA SUNDA DI KABUPATEN BANDUNG
}

\author{
Wagiati, Wahya, dan Sugeng Riyanto \\ Fakultas Ilmu Budaya Universitas Padjadjaran \\ email: wagiati@unpad.ac.id
}

\begin{abstract}
Abstrak
Penelitian ini bertujuan untuk membuktikan vitalitas (daya hidup, tingkat kesehatan) bahasa Sunda menghadapi bahasa Indonesia. Penelitian itu berancangan kuantitatif dengan menggunakan dua variabel bebas, yakni penggunaan bahasa Sunda yang dihadapkan dengan bahasa Indonesia dan kelompok pengguna bahasa Sunda sebagai bahasa pertama, yakni keluarga asli Sunda yang bermukim di Kabupaten Bandung, Jawa Barat. Variabel terikatnya adalah pilihan bahasa, yakni bahasa Sunda atau bahasa Indonesia. Hasil penelitian membuktikan bahwa vitalitas bahasa Sunda kuat pada ranah kekeluargaan, transaksional, dan kekariban; tetapi lemah pada ranah kedinasan dan orang tidak dikenal. Dari segi kesepakatan, ranah keluarga, transaksional, dan kekariban juga menduduki tempat yang tinggi dibandingkan ranah kedinasan dan orang tidak dikenal. Penggunaan terbanyak bahasa Sunda ada pada ranah kekeluargaan, terutama pada saat informan berbicara dengan kakek/nenek dan ayah/ibu. Bahasa Sunda berkurang vitalitasnya pada ranah kedinasan dan ranah orang tidak dikenal.
\end{abstract}

Kata kunci: vitalitas bahasa, bahasa pertama, bahasa Sunda

\section{THE VITALITY OF THE SUNDANESE LANGUAGE IN BANDUNG REGENCY}

\begin{abstract}
This study aims to prove the vitality of the Sundanese language to face the Indonesian language. This was a quantitative study involving two independent variables, namely the use of the Sundanese language to confront the Indonesian language and groups of users of the Sundanese language as the first language, namely the native Sundanese families living in Bandung Regency, West Java. The dependent variable was the choice of language, i.e. the Sundanese or Indonesian language. The results prove that the vitality of the Sundanese language is strong in the family, transaction, and closeness domains; but it is weak in the official domain and that related to strangers. In terms of agreement, the family, transaction, and closeness domains also occupy a high position compared to the official domain and that related to strangers. The use of the Sundanese language with the highest frequency is in the family domain, especially when the informants talk with grand parents and fathers/mothers. The vitality of the Sundanese language lessens in the official domain and that related to strangers.
\end{abstract}

Keywords: language vitality, first language, Sundanese language

\section{PENDAHULUAN}

Bahasa sebagai objek penelitian tidak pernah habis untuk diselidiki karena, dalam penelitian bahasa, sudut pandang da- pat menciptakan objek penelitian (Kridalaksana, 2002). Hal itulah yang membuat penelitian linguistik beragam dan marak. Bahasa dapat dikaji dari aspek struktur 
belaka, misalnya struktur fonem, morfem, klausa, kalimat, paragraf, dan wacana. Kajian itu tidak dikaitkan dengan faktor lain di luar bahasa karena bahasa dikaji secara murni dan intern. Kajian itulah yang mendasari fonologi, morfologi, sintaksis, kajian struktur paragraf dan wacana. Kajian tentang makna juga dapat bersifat murni sebagaimana dikaji dalam semantik.

Bahasa dapat juga dikaji secara eksternal. Dalam hal ini bahasa dikaitkan dengan faktor di luar bahasa. Bahasa pada prinsipnya merupakan alat komunikasi yang selalu muncul dan diperlukan jika paling tidak ada dua orang yang menguasai bahasa yang sama. Komunikasi merupakan kegiatan yang bersifat sosial sehingga kelancaran penggunaan bahasa tak ayal dipengaruhi faktor sosial. Salah satu bidang yang mengkaji bahasa dikaitkan dengan faktor sosial dalam proses komunikasi adalah sosiolinguistik. Sosiolonguistik yang merupakan bidang interdisipliner mengkaji bahasa yang digunakan dalam fungsi primernya, yakni sebagai alat komunikasi.

Penggunaan bahasa merupakan salah satu pokok yang diteliti dalam sosiolinguistik. Penggunaan bahasa itu berkaitan dengan pemilihan bahasa yang menurut penutur paling cocok digunakan dalam ranah tertentu. Masyarakat tutur di Indonesia sudah terbiasa menggunakan beberapa bahasa. Para penutur itu berdwibahasawan atau bahkan beranekabahasawan. Situasi diglosia merupakan gejala yang sudah biasa di Indonesia. Pada situasi kebahasaan seperti itu penutur tahu betul kapan menggunakan bahasa yang mana pada ranah yang mana tanpa menimbulkan kekeliruan. Pemertahanan bahasa juga merupakan topik penelitian yang diminati dalam sosiolinguistik. Bahasa Indonesia di Indonesia semakin kuat kedudukannya. Sebagian media massa baik tulis, dengar, pandang dengar kini menggunakan bahasa Indonesia. Bahasa
Indonesia tak ayal mendesak penggunaan bahasa daerah.

Bahasa Sunda sebagai bahasa daerah kedua terbesar sesudah bahasa Jawa juga dapat terdesak oleh bahasa Indonesia. Di Sekolah Dasar bahasa Sunda diberikan sebagai mata pelajaran muatan lokal yang diberikan sekali seminggu di wilayah provinsi Jawa Barat. Jumlah jam yang terlalu sedikit itu sangat tidak cukup. Bahasa terbaik dipelajari secara alamiah alih-alih di kelas. Lingkungan juga sangat mendukung terpeliharanya bahasa. Jika orang sekitar menggunakan bahasa Sunda, misalnya, anak-anak yang ada di sana pasti juga menguasai bahasa Sunda. Masyarakat sendiri yang berperan penting dalam pemertahanan bahasa.

Kabupaten Bandung merupakan konsentrasi penduduk yang merupakan keturunan suku Sunda, penutur bahasa Sunda. Tidak dapat dipungkiri masyarakat Sunda di kabupaten itu setiap hari, siang dan malam, mendengar dan membaca bahasa Indonesia dari berbagai media. Orang yang datang ke lingkungan itu pasti juga akan mendengar bahasa Sunda. Sebagian besar orang tua Sunda menegur orang yang baru ditemuinya juga dalam bahasa Sunda. Sebenarnya tidak ada alasan untuk adanya penyusutan penggunaan bahasa Sunda. Untuk itu sangat menarik untuk meneliti secara kuantitatif sejauh mana bahasa Sunda masih bertahan di keluarga-keluarga Sunda yang berada di kabupaten Bandung. Sekuat apa bahasa Sunda mampu bertahan dari serbuan bahasa Indonesia. Hasil penelitian itu dapat dijadikan titik tolak pengambilan kebijakan dari pemangku kepentingan yang berkaitan dengan pemertahanan budaya dan bahasa. Penelitian yang dilakukan ini bertujuan untuk mengkaji sejauh mana bahasa bertahan sebagai alat komunikasi pada masyarakat Sunda di Kabupaten Bandung.

Riyanto (2013) menjelaskan bahwa bahasa Sunda dipertahankan oleh para 
mahasiswa Fakultas Ilmu Budaya Unpad di banyak ranah. Para mahasiswa merupakan kelompok anak muda yang akan menjadi pemimpin di masa mendatang sehingga hasil penelitian itu membuktikan bahwa mahasiswa merupakan pihak yang penting dalam pemertahanan bahasa. Sofyan dkk. (2014) menyatakan bahwa mahasiswa Unpad yang belajar di kampus Jatinangor sedikit banyak menguasai bahasa Sunda. Kepungan bahasa dan budaya Sunda di Jatinangor memaksa mereka belajar bahasa Sunda. Penelitian yang akan dilakukan berskala lebih besar karena menjangkau ratusan keluarga yang berbahasa pertama Sunda. Alur penelitiannya dapat dilihat pada bagan yang berikut.

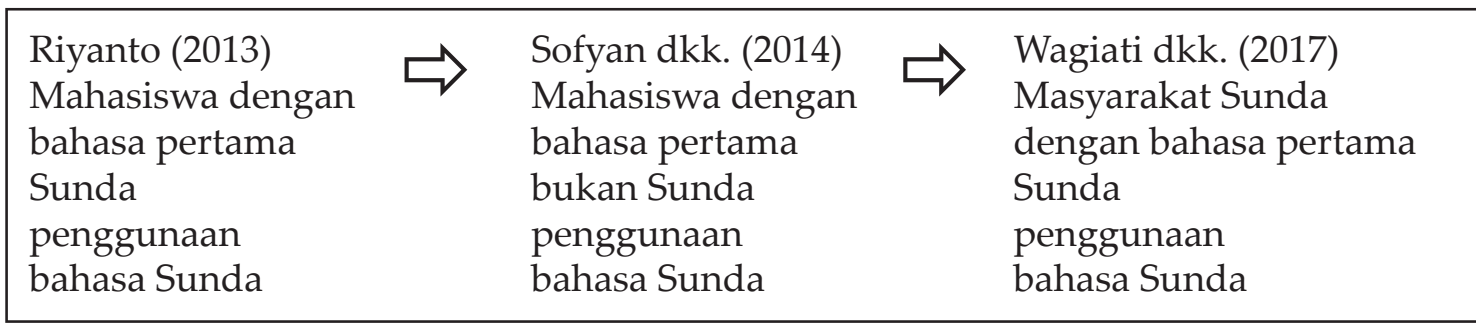

Masalah yang diteliti adalah penggunaan bahasa Sunda di kalangan keluarga Sunda di kabupaten Bandung yang berbahasa pertama Sunda di lingkungan keluarga, di lingkungan sekitar tempat tinggal, perjalanan, sekolah, dan kantor pemerintahan. Ketegangan muncul pada kemungkinan pemilihannya, yakni apakah mereka menggunakan bahasa Sunda atau bahasa Indonesia.

Pertanyaan penelitian dapat dirumuskan sebagai berikut. Pertama, dijawab seberapa banyak bahasa Sunda digunakan dalam keluarga inti. Kedua, diteliti juga sejauh mana bahasa Sunda digunakan di sekitar tempat tinggal. Ketiga, dijelaskan seberapa banyak bahasa Sunda digunakan di perjalanan, sekolah, dan kantor. Akan dikaji pula apakah ada perbedaan penggunaan bahasa Sunda pada ranah akrab dan ranah tidak akrab (formal).

Bahasa dalam penelitian ini bersifat makro, yakni sebagai maujud yang utuh dan tidak dilihat unsur-unsurnya. Penelitian ini dapat menunjukkan bahwa kekhawatiran menurunnya minat masyarakat untuk menggunakan bahasa pertama, khususnya Sunda, tidak beralasan. Masyarakat Sunda menunjukkan diri mereka sebagai kelompok masyarakat tutur yang mampu memilih bahasa yang tepat sesuai dengan ranahnya. Situasi diglosia tidak bocor. Bahasa Indonesia dan bahasa Sunda memiliki ranahnya masing-masing.

Penelitian ini berada di dalam wilayah keilmuan sosiolinguistik dan sejalan dengan alur penelitian yang ditapaki oleh Universitas Padjadjaran, yakni bahasa sebagai alat komunikasi dan khususnya bahasa Sunda sebagai alat komunikasi. Sosiolingustik merupakan bidang linguistik yang memusatkan kajiannya pada penggunaan bahasa dalam masyarakat (Mesthrie 2001). Bidang interdisipliner itu masuk melalui pintu gerbang linguistik dan menyertakan faktor-faktor sosial yang menyertai penggunaan bahasa (Kridalaksana, 2009). Sebagai alat komunikasi bahasa sangat tidak lengkap jika tidak menyertakan faktor sosial. Bahasa ada karena keperluan yang bersifat sosial. Jika manusia tidak hidup dengan manusia lain, bahasa tidak diperlukan keberadaannya.

Masyarakat tutur yang berada dalam era moderen, terutama yang bermukim di kota, nyaris tidak ada yang ekabahasawan. Para penuturnya dapat dipastikan menguasai lebih dari satu bahasa, dwiba- 
hasawan, atau bahkan anekabahasawan (Grosjean, 2001). Ekabahasawan pada masa kini merupakan kelangkaan. Di berbagai belahaan dunia, dwibahasawan merupakan keharusan, meingingat dunia internasional semakin maya batasnya dan masyarakat dunia memerlukan bahasa pengantar yang paling banyak digunakan, yakni bahasa Inggris. Jadi, selain bahasa pertama, warga masyarakat harus menguasai bahasa Inggris.

Penggunaan bahasa berkaitan erat dengan pemilihan bahasa. Hal itu tentu saja terjadi pada penutur yang sedikitnya berdwibahasa. Pemilihan bahasa itu berkaitan baik faktor sosial maupun psikologis. Dalam kajian pemilihan bahasa perlu dideskripsikan hubungan antara gejala pemilihan bahasa dan faktor-faktor sosial, budaya, dan situasional dalam masyarakat dwibahasa atau anekabahasa (Mardikantoro, 2012). Masalah bahasa sebagai simbol keetnisan dan loyalitas bahasa berkaitan erat dengan sikap penutur terhadap bahasanya (Thomason 2001).

Bahasa dianggap memiliki vitalitas (daya hidup, tingkat kesehatan) jika bahasa itu sungguh-sungguh digunakan sebagai alat komunikasi oleh masyarakat penuturnya (Grenoble dan Whaley, 2006). Bahasa di dunia ini memiliki berbagai ragam vitalitas dari yang tinggi hingga yang rendah dan bahkan ada bahasa yang nyaris mati karena tidak ada lagi penutur yang menggunakannya karena berbagai penyebab. Bahasa yang masih digunakan oleh semua tingkatan umur dianggap memiliki tingkat vitalitas yang aman.

Bahasa merupakan maujud yang dinamis. Dalam masyarakat, bahasa dapat bertahan dan juga dapat bergeser atau bahkan hilang karena tidak ada penuturnya (Sumarsono 2000, Sumarsono dan Partana 2002). Bahasa Melayu Loloan di Bali bertahan dari serbuan bahasa Bali tetapi goyah menghadapi bahasa Indonesia. Bahasa Melayu Loloan identik dengan Islam sementara masyarakat Bali beragama
Hindu. Bahasa Indonesia tidak dikaitkan dengan agama tertentu sehingga di masjid pun bahasa Indonesia mulai digunakan di Loloan. Pemertahanan bahasa erat kaitannya dengan ranah yang berkaitan dengan pilihan bahasa (Rokhman, 2009).

Bahasa Sunda merupakan bahasa terbesar kedua setelah bahasa Jawa di Indonesia (Wahya, 1995, 2005, 2015; Dienaputra 2012). Sebagian besar penduduk yang bermukim di provinsi Jawa Barat menguasai bahasa Sunda. Wilayah Priangan merupakan pusat konsentrasi pengguna bahasa Sunda. Dengan persebaran yang sangat luas tentu bahasa Sunda memiliki variasi geografis (dialek) tetapi perbedaan dialek tidak membuat mereka menjadi tidak saling mengerti. Sebagai bahasa daerah, meskipun penuturnya terbesar kedua di Indonesia, keberadaannya semakin terdesak oleh bahasa nasional bahasa Indonesia sehingga pergeseran bahasa daerah tinggal menunggu waktu (Gunarwan, 2006). Masyarakat kabupaten Bandung merupakan konsentrasi pengguna bahasa Sunda yang menempati posisi strategis dalam pemertahanan bahasa Sunda. Jika mereka mampu tetap menggunakan bahasa Sunda pada ranah-ranah yang memang semestinya ditempati bahasa itu, pergeseran bahasa dapat dibendung (bandingkan Dienaputra, 2012).

\section{METODE}

Penelitian ini menggunakan ancangan kantitatif. Ancangan kuantitatif biasa digunakan dalam penelitian pemertahanan bahasa. Peneliti menentukan peubah bebas dan peubah terikatnya agar dapat mengontrolnya dengan akurat.

Para pembahan dihadapkan pada daftar tanyaan yang jawabannya hanya dua yakni bahasa Sunda atau bahasa Indonesia yang mereka gunakan sesuai situasi yang diberikan. Data berupa angka nominal yakni 1 atau 2. Angka 1 berarti bahasa Sunda yang digunakan, angka 
2 bahasa Indonesia. Daftar pertanyaan diberikan dalam bentuk manual.

Ancangan penelitian yang digunakan dalam penelitian ini adalah kuantitatif. Data yang diperoleh akan berbentuk angka (1 = bahasa Sunda dan 2 = bahasa Indonesia). Penentuan dua bahasa itu merupakan variabel bebas, yakni variabel yang ditentukan sendiri oleh peneliti. Variabel bebas kedua adalah kelompok pembahan (responden), yakni ayah, ibu, dan anak. Variabel terikatnya adalah pemilihan yang mereka lakukan, yakni bahasa Sunda (pilihan 1) atau bahasa Indonesia (pilihan 2). Dari rata-rata dan analisis variasi akan diperoleh persebarannya dan ketiga kelompok itu dapat dibandingkan sehingga akan terlihat variasi persebarannya.

Instrumen pengambilan data berupa pertanyaan yang jawabannya hanya ada dua kemungkinan, yakni 1 = bahasa Sunda dan 2 = bahasa Indonesia. Jawabannya berbentuk pilihan ganda yang hanya berisi dua kemungkinan. Dua bahasa itulah yang kemungkinan besar digunakan pembahan. Ranahnya berkaitan dengan keluarga, lingkungan sekitar rumah, dan lingkungan formal seperti sekolah dan kantor.

Data akan diolah dengan pengolah data statistik yang mampu menampilkan rata-rata hitung. Dengan itu persebaran hasil dapat diketahui. Agar hasilnya lebih terinci diperlukan pula analis variansi untuk melihat perbedaan persebaran kelompok. Dari penghitungan itu akan terlihat kehomogenan perangai kedua kelompok itu.

Data dikumpulkan satu per satu dari pembahan. Pembahan dihadapkan pada sebuah daftar tanyaan yang diketik. Sebelum mulai, pembahan diberi penjelasan apa yang harus dilakukannya.

Purposive sampling digunakan dalam penelitian ini. Peneliti memilih sendiri pembahan sesuai dengan tujuan penelitian. Pembahan harus menguasai bahasa Sunda dan bahasa Indonesia Sebelum pengambilan data, pembahan disodori beberapa pertanyaan berkaitan dengan penguasaan bahasa Sunda dan Indonesia. Pembahan terdiri atas sang ayah, sang ibu, dan sang anak. Untuk penelitian disertakan 120 keluarga; itu berarti 360 pembahan.

Instrumen pengambilan data berupa daftar tanyaan yang dirancang sesuai dengan pertanyaan penelitian. Jumlah pertanyaan tersebar merata sesuai dengan ranah. Pertanyaan berjumlah lima puluh. Sebelum program yang sesungguhnya dimulai ada instruksi yang jelas dan beberapa kalimat contoh.

Validitas data diukur dari proses pengambilan data, yakni pembahan mengerti sungguh-sungguh apa yang harus dilakukan dan berkonsentrasi penuh menghadapi tugas yang diberikan. Uraian situasi juga memengaruhi validitas. Instruksi diberikan sejelas mungkin agar validitas meningkat. Sebelum penelitian yang sesungguhnya dilakukan, instrumen dicobakan dulu apakah itu dapat digunakan sesuai tujuan. Data yang diperoleh diolah oleh pemrogram SPSS (Statistic Program for Social Sciences, 2007) berkaitan dengan rata-rata hitung dan simpangan baku.

Lokasi riset adalah Kabupaten Bandung yang akan dibagi menjadi lima titik penelitian yakni Kabupaten Bandung bagian timur, bagian selatan, barat, utara, dan tengah. Riset dilaksanakan antara bulan April 2017 hingga Juni 2017.

Instrumen penelitian berupa daftar tanyaan. Informan yang terseleksi sesuai dengan kriteria memilih bahasa yang paling sering digunakan, yakni (1) bahasa Sunda dan (2) bahasa Indonesia dalam berbagai ranah dan lawan bicara. 
Tabel 1. Lawan Bicara dan Ranah

\begin{tabular}{|c|c|}
\hline No. & Lawan berbicara \\
\hline 1. & Kakek/Nenek di rumah \\
\hline 2. & Kakek/Nenek di pusat keramaian \\
\hline 3. & $\begin{array}{l}\text { Kakek/Nenek di kantor kelurahan/ } \\
\text { kecamatan }\end{array}$ \\
\hline 4. & Bapak/Ibu di rumah \\
\hline 5. & Bapak/Ibu di pusat keramaian \\
\hline 6. & $\begin{array}{l}\text { Bapak/Ibu di kantor kelurahan/ } \\
\text { kecamatan }\end{array}$ \\
\hline 7. & Saudara kandung di rumah \\
\hline 8. & $\begin{array}{l}\text { Saudara kandung di pusat } \\
\text { keramaian }\end{array}$ \\
\hline 9. & $\begin{array}{l}\text { Saudara kandung di kantor } \\
\text { kelurahan/kecamatan }\end{array}$ \\
\hline 10. & Teman dekat di RT/RW yang sama \\
\hline 11. & Tetangga (tua) \\
\hline 12. & Tetangga (muda) \\
\hline 13. & Tetangga (sebaya) \\
\hline 14. & Tetangga (anak-anak) \\
\hline 15. & Tukang ojeg yang dikenal baik \\
\hline 16. & Tukang ojeg yang tidak dikenal \\
\hline 17. & Penjaga toko yang dikenal baik \\
\hline 18. & Penjaga toko yang tidak dikenal baik \\
\hline 19. & Pedagang di pasar tradisional \\
\hline 20. & Guru di kantor sekolah \\
\hline 21. & Guru di luar kantor sekolah \\
\hline 22. & $\begin{array}{l}\text { Pegawai kelurahan/kecamatan di } \\
\text { kantor }\end{array}$ \\
\hline 23. & $\begin{array}{l}\text { Pegawai kelurahan/kecamatan di } \\
\text { luar kantor }\end{array}$ \\
\hline 24. & Orang yang tidak dikenal \\
\hline
\end{tabular}

\section{HASIL DAN PEMBAHASAN \\ Ranah Kekeluargaan}

Pada Tabel 2 tersurat bahwa posisi bahasa Sunda kuat dalam ranah kekeluargaan (dengan kakek-nenek, ayah-ibu, dan saudara kandung) (rerata 1,21). Yang paling kuat posisi bahasa Sunda adalah pada saat bahasa itu digunakan oleh informan dalam berkomunikasi dengan kakek dan nenek di rumah (rerata 1,06); mereka nyaris selalu menggunakan bahasa Sunda.
Dilihat dari simpangan baku $(0,24)$ ranah itu juga paling kecil sehingga tingkat kesepakatannya juga paling tinggi dalam memutuskan untuk menggunakan bahasa Sunda. Dengan saudara kandung di kantor kelurahan informan paling sedikit menggunakan bahasa Sunda (rerata 1,36; simpangan baku 0,48), tetapi jika di rumah penggunaan bahasa Sunda meningkat dengan tingkat kesepakatan yang juga lebih tinggi (rerata 1,19; simpangan baku $0,41)$.

Tabel 2. Penggunaan Bahasa Sunda pada Ranah Kekeluargaan

\begin{tabular}{ccc}
\hline Ranah & Rerata & s.b. \\
\hline 1 & 1.06 & 0.24 \\
2 & 1.10 & 0.30 \\
3 & 1.12 & 0.33 \\
4 & 1.13 & 0.34 \\
5 & 1.27 & 0.45 \\
6 & 1.32 & 0.47 \\
7 & 1.19 & 0.41 \\
8 & 1.32 & 0.47 \\
9 & 1.36 & 0.48 \\
\hline Rerata & 1.21 & 0.39 \\
\hline
\end{tabular}

Keterangan:

s.b. : simpangan baku

\section{Ranah Kekariban}

Hasil penggunaan bahasa Sunda pada ranah kekariban ada pada Tabel 3. Ranah kekariban meliputi penggunaan bahasa Sunda dengan teman, tetangga, dan guru. Bahasa Sunda paling banyak digunakan (rerata 1,12; s.b. 0,33) dengan teman dekat satu RT/RW dan dengan tetangga tua (rerata 1,13; s.b. 0,34). Dengan tetangga sebaya juga relatif banyak digunakan bahasa Sunda (rerata 1,15), tapi tingkat kekompakan rendah (s.b. 0,75). Dibandingkan dengan teman, penggunaan bahasa Sunda dengan guru lebih sedikit (di kantor sekolah rerata 1,73 dan s.b. 0,45; di luar kantor sekolah rerata 1,57 dan s.b. 
0,50); tingkat kesepakatannya relatif rendah dilihat dari angka simpangan baku. Dengan guru tampaknya lebih banyak digunakan bahasa Indonesia.

Tabel 3. Penggunaan Bahasa Sunda pada Ranah Kekariban

\begin{tabular}{ccc}
\hline Ranah & Rerata & s.b. \\
\hline 10 & 1.12 & 0.33 \\
11 & 1.13 & 0.34 \\
12 & 1.32 & 0.47 \\
13 & 1.15 & 0.75 \\
14 & 1.34 & 0.48 \\
20 & 1.73 & 0.45 \\
21 & 1.57 & 0.50 \\
\hline Rerata & 1.34 & 0.47 \\
\hline
\end{tabular}

Keterangan:

s.b. : simpangan baku

\section{Ranah Transaksional}

Ranah transaksional berisi percakapan dengan tukang ojek, penjaga toko, dan pedagang di pasar tradisional.

Tabel 4. Penggunaan Bahasa Sunda pada Ranah Kekariban Transaksional

\begin{tabular}{ccc}
\hline Ranah & Rerata & s.b. \\
\hline 15 & 1.11 & 0.31 \\
16 & 1.30 & 0.46 \\
17 & 1.25 & 0.43 \\
18 & 1.61 & 0.49 \\
19 & 1.11 & 0.31 \\
\hline Rerata & 1.28 & 0.40 \\
\hline
\end{tabular}

Keterangan:

s.b. : simpangan baku

Pada Tabel 4 terbaca bahwa bahasa Sunda paling banyak digunakan saat informan berbicara dengan tukang ojek yang dikenal baik dan dengan pedagang di pasar tradisional. Rerata untuk kedua ranah itu sama $(1,11)$ dan simpangan bakunya juga sama $(0,31)$. Dari simpangan baku tersurat bahwa informan memiliki tingkat kesepakatan yang cukup tinggi. Bahasa Indonesia lebih banyak digunakan saat informan berbicara dengan penjaga toko yang tidak dikenal meskipun dengan tingkat kesepakatan yang relatif rendah.

\section{Ranah Kedinasan}

Ranah kedinasan berisi percakapan dengan pegawai kelurahan/kecamatan di dalam kantor maupun di luar kantor. Hasil penggunaan bahasa Sunda pada ranah kedinasan terbaca pada Tabel 5. Dari rerata terlihat bahwa bahasa Indonesia lebih banyak digunakan pada ranah kedinasan. Ternyata di dalam kantor bahasa Sunda lebih sedikit digunakan daripada di luar kantor.

Tabel 5. Penggunaan Bahasa Sunda pada Ranah Kedinasan

\begin{tabular}{ccc}
\hline Ranah & rata & s.d. \\
\hline 22 & 1.57 & 0.50 \\
23 & 1.46 & 0.50 \\
\hline Rerata & 1.52 & 0.50 \\
\hline
\end{tabular}

Keterangan:

s.b. : simpangan baku

\section{Ranah Orang Tidak Dikenal}

Pada Tabel 6 terbaca bahwa informan lebih banyak menggunakan bahasa Indonesia dengan orang yang tidak dikenal (rerata 1,71 dan s.b. 0,45). Dengan guru di kantor sekolah (lihat Tabel 3) informan lebih banyak menggunakan bahasa Indonesia daripada bahasa Sunda (rerata 1,73 dan s.b. 0,45). Tingkat penggunaan bahasa Indonesia pada kedua ranah itu nyaris sama.

Tabel 6. Penggunaan Bahasa Sunda kepada Orang Tidak Dikenal

\begin{tabular}{ccc}
\hline Ranah & Rerata & s.b. \\
\hline 24 & 1.71 & 0.45 \\
\hline
\end{tabular}

Keterangan:

s.b. : simpangan baku 


\section{SIMPULAN}

Vitalitas bahasa Sunda kuat pada ranah kekeluargaan, transaksional, dan kekariban; tetapi lemah pada ranah kedinasan dan orang tidak dikenal. Dari segi kesepakatan, ranah keluarga, transaksional, dan kekariban juga menduduki tempat yang tinggi dibandingkan ranah kedinasan dan orang tidak dikenal. Penggunaan terbanyak bahasa Sunda ada pada ranah kekeluargaan, terutama pada saat informan berbicara dengan kakek/nenek dan ayah/ibu. Bahasa Sunda berkurang vitalitasnya pada ranah kedinasan dan ranah orang tidak dikenal. Bahasa Sunda paling sedikit digunakan pada saat informan berbicara dengan guru di dalam kantor sekolah. Vitalitas bahasa Sunda dapat terjaga jika penutur bahasa Sunda menggunakan sebanyak mungkin bahasa Sunda di ranah kekeluragaan pada saat mereka berkomunikasi dengan ayah/ibu, kakek/nenek, dan saudara kandung.

\section{UCAPAN TERIMA KASIH}

Penelitian yang hasilnya disajikan pada artikel ini didanai oleh Hibah Internal Universitas Padjadjaran tahun anggaran 2017/2018. Untuk itu terima kasih disampaikan kepada Rektor Universitas Padjadjaran, Dekan Fakultas Ilmu Budaya Unpad, Direktur Riset, Pengabdian pada Masyarakat, dan Inovasi Unpad, dan Manajer Riset, Pengabdian pada Masyarakat, dan Inovasi Fakultas Ilmu Budaya Unpad.

\section{DAFTAR PUSTAKA}

Dienaputra, R.D. 2012. Sunda: Sejarah, Budaya, dan Politik. Cetakan Kedua. Jatinangor: Sastra Unpad Press.

Grenoble, LA. dan L.J. Whaley. 2006. Saving Language: An Introduction to Language Revitalization. Cambridge: Cambridge University Press.

Grosjean, F. 2001. Bilingualism, Individual. Dalam R. Mesthrie (ed.) Concise Ency- clopedia of Sociolinguistics. Amsterdam, New York: Elsevier, hlm. 10-15.

Gunarwan, A. 2006. Kasus-Kasus Pergeseran Bahasa Daerah Akibat Persaingan dengan Bahasa Indonesia. Linguistik Indonesia, Jurnal Ilmiah Masyarakat Lingustik Indonesia, hlm. 106-197.

Kridalaksana, H. 2002. Struktur, Ketegori, dan Fungsi dalam Teori Sintaksis. Jakarta: Unika Atma Jaya.

Kridalaksana, H. 2009. Kamus Linguistik. Edisi Keempat, Cetakan Kedua. Jakarta: Gramedia.

Mardikantoro, H.B. 2012. Bentuk Pergeseran Bahasa Jawa Masyarakat Samin dalam Ranah Keluarga, LITERA, Jurnal Penelitian Bahasa, Sastra, dan Pengajarannya, Vol. 11, No. 2, hlm. 204-215.

Mesthrie, R. 2001. Sosiolinguistics: History and Overview. Dalam R. Mesthrie (ed.) Concise Encyclopedia of Sociolinguistics. Amsterdam, New York: Elsevier, hlm. 1-4.

Riyanto, S. 2013. Penggunaan Bahasa Sunda oleh Mahasiswa yang Berbahasa Pertama Sunda. Laporan Penelitian Hibah Bersaing Fakultas Ilmu Budaya Unpad.

Rokhman, F. 2009. Pergeseran Bahasa Indonesia di Era Global dan Implikasinya terhadap Pembelajaran. http:// faturrokhmancenter.wordpress.com (diunduh tanggal 13 Mei 2013).

Sofyan, A.N., T. Suparman, dan S. Riyanto. 2014. Penyebaran Bahasa Sunda pada Mahasiswa Unpad yang Berbahasa Pertama Bahasa Lain Laporan Penelitian Hibah Bersaing Fakultas Ilmu Budaya Unpad.

Sumarsono dan P. Partana. 2002. Sosiolinguistik. Yogyakarta: Sabda.

Sumarsono. 2000. Sikap dan Perilaku Tutur Penutur Bahasa Melayu Loloan terhadap Bahasanya dan BahasaBahasa Lainnya. Dalam Kajian Serba Linguistik untuk Anton Moeliono Pereksa Bahasa. Jakarta: BPK Gunung Mulia. 
Thomason, S.G. 2001. Language Contact, an Introduction. Edinburg: Edinburg University Press.

Wahya. 2005. Inovasi dan Difusi GeografisLeksikal Bahasa Melayu dan Bahasa
Sunda di Perbatasan Bogor-Bekasi: Kajian Geolinguistik. Disertasi Universitas Padjadjaran bandung.

Wahya. 2015. Bahasa dalam Perspektif Geografis. Bandung: CV Semiotika. 